\title{
Lifetime risk of mortality due to different levels of alcohol consumption in seven European countries: implications for low-risk drinking guidelines
}

Kevin D Shield ${ }^{1 *}$, Gerrit Gmel ${ }^{2}$, Gerhard Gmel ${ }^{3}$, Pia Mäkelä ${ }^{4}$, Charlotte Probst ${ }^{1}$, Robin Room ${ }^{5,6}$, Jürgen Rehm ${ }^{1,7-11}$

1. Institute for Mental Health Policy Research, Centre for Addiction and Mental Health, Toronto, Canada

2. School of Electrical Engineering and Telecommunications, University of New South Wales, Kensington, Australia

3. Epidemiology and Statistics Section, Addiction Suisse, Lausanne, Switzerland

4. Alcohol, Drugs and Addictions Unit, National Institute for Health and Welfare THL, Helsinki, Finland

5. Centre for Alcohol Policy Research, La Trobe University, Melbourne, Australia

6. Centre for Social Research on Alcohol and Drugs, Stockholm University, Sweden

7. Institute for Clinical Psychology and Psychotherapy, TU Dresden, Chemnitzer Str. 46, 01187 Dresden, Germany

8. Campbell Family Mental Health Research Institute, CAMH, 250 College Street, Toronto, ON M5T 1R8, Canada

9. Institute of Medical Science (IMS), University of Toronto, Medical Sciences Building, 1 King's College Circle, Room 2374, Toronto, ON M5S 1A8, Canada

10. Department of Psychiatry, University of Toronto, 250 College Street, 8th Floor, Toronto, ON M5T 1R8, Canada

11. Dalla Lana School of Public Health, University of Toronto, 155 College Street, 6th Floor, Toronto, ON M5T 3M7, Canada

\section{* Correspondence to:}

Dr. Kevin D. Shield

International Agency for Research on Cancer

Section of Cancer Surveillance

150 Cours Albert Thomas,

Latarjet building, Room L110

69372 Lyon CEDEX 08,

France

Tel: $+33(0) 472738485$ ext. 8886

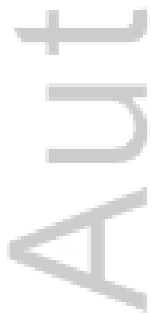

This is the author manuscript accepted for publication and has undergone full peer review but has not been through the copyediting, typesetting, pagination and proofreading process, which may lead to differences between this version and the Version of Record. Please cite this article as doi: 10.1111/add.13827

This article is protected by copyright. All rights reserved. 


\section{Summary}

Background and aims: Low-risk alcohol drinking guidelines require a scientific basis that extends beyond individual or group judgements of risk. Lifetime mortality risks, judged against established thresholds for acceptable risk, may provide such a basis for guidelines. Therefore, the aim of this study was to estimate alcohol mortality risks for seven European countries based on different average daily alcohol consumption amounts.

Methods: The maximum acceptable voluntary premature mortality risk was determined to be 1 in 1,000 , with sensitivity analyses of 1 in 100 . Lifetime mortality risks for different alcohol consumption levels were estimated by combining disease-specific relative risk and mortality data for seven European countries with different drinking patterns (Estonia, Finland, Germany, Hungary, Ireland, Italy, and Poland). Alcohol consumption data were obtained from the Global Information System on Alcohol and Health, relative risk data from meta-analyses, and mortality information from the World Health Organization.

Results: The variation in the lifetime mortality risk at drinking levels relevant for setting guidelines was less than that observed at high drinking levels. In Europe, the percentage of adults consuming above a risk threshold of 1 in 1,000 ranged from $20.6 \%$ to $32.9 \%$ for women and from $35.4 \%$ to $54.0 \%$ for men. Lifetime risk of premature mortality under current guideline maximums ranged from 2.5 to 44.8 deaths per 1,000 women in Finland and Estonia respectively, and from 2.9 to 35.8 deaths per 1,000 men in Finland and Estonia respectively. If based upon an acceptable risk of 1 in 1,000, guideline maximums for Europe should be 8-10 g/day for women and 15-20 $\mathrm{g} /$ day for men.

Conclusions: If low-risk alcohol guidelines were based on an acceptable risk of 1 in 1,000 premature deaths, then maximums for Europe should be 8-10 g/day for women and 15-20 g/day for men, and some of the current European guidelines would require downward revision.

Keywords: Guideline; Alcohol; Mortality; Chronic Disease; Infection; Wounds; Injuries 


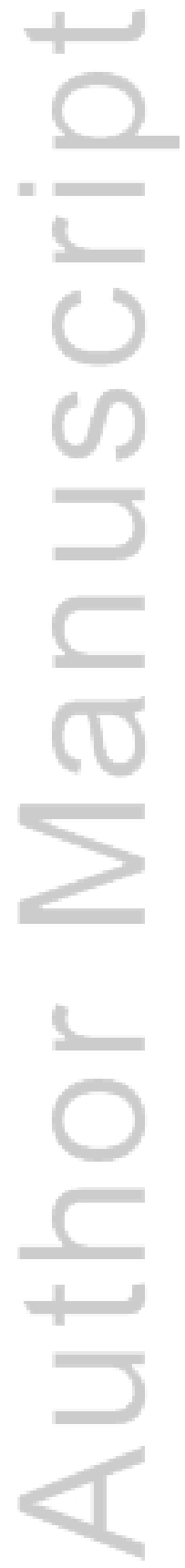

This article is protected by copyright. All rights reserved. 


\section{Introduction}

The consumption of alcohol causes a substantial burden of communicable and noncommunicable diseases, as well as injuries [1-4]. In hopes of reducing this burden, many countries have implemented drinking guidelines [5,6]. The implementation of such guidelines fits well with the modern ideal of a consumer society, with well-informed consumers putatively conforming their behaviour based on advice from governmental, research, and professional sources [5]. Over time, the aim of drinking guidelines has changed from the designations of "safe" or "sensible" guidelines to the designation of "low-risk" guidelines, as research has indicated for a number of health outcomes, such as gastrointestinal diseases, cancer and injuries, that there is no safe level of alcohol consumption [1, 7-9].

There has been a lack of consistency on how drinking guidelines are formulated [10]. Differences in the methodologies used to formulate guidelines contribute to variations in guidelines between countries and to inconsistent information being disseminated about what constitutes low-risk drinking, creating confusion for consumers and health care professionals. While there have been thorough efforts trying to summarize the available empirical evidence (e.g., $[11,12])$, guideline thresholds of low-risk alcohol consumption are often set by a group of independent experts, and in some cases community stakeholders (i.e. blue ribbon committees), based on average alcohol consumption relative risk (RR) curves for all-cause or selected disease mortality. 
The RR curves used to estimate the threshold for low-risk drinking are problematic due to two factors. Firstly, the all-cause mortality RRs are estimated based on large, non-representative cohort studies; these studies are constructed for ease of follow-up, and their findings may be biased when applied to the general population by the over-representation of deaths that occur in the middle class population compared to other segments of the general population, such as deaths caused by cardiovascular diseases $[13,14]$. Secondly, these RR estimates are usually derived from large cohort studies which took place in one country; however, many country-specific factors determine the impact on health of the average volume of alcohol consumed, contributing to country variations in cause-of-death structures. In particular, genetics can modify the impact of alcohol on health. For example, for populations with a high prevalence of the ALDH2 gene (the "flushing gene"), alcohol can have a much higher impact on the development of cancer $[15,16]$. Additionally, alcohol interacts with other risk factors, such as smoking and drug use, and these interactions determine, in part, the impact of alcohol on health $[17,18]$. Furthermore, environmental factors modify the impact of alcohol on health (e.g., highway safety modifies the impact of alcohol on traffic injuries) [7]. Lastly, competing risks (i.e., mortality that occurs before an alcohol-attributable death would be observed) modify the impact of alcohol on health. For instance, mortality from cancer generally occurs later in life than does mortality from injuries, and, thus, alcohol's impact on cancer is more strongly impacted by competing risks when compared to other alcohol-related diseases and injuries. However, the impact of these factors on cause-of-death structures at low levels of alcohol consumption $(<20$ grams of pure alcohol per day) is unknown. 
Due to the limitations in the current guidelines' methodologies, the objectives of this paper are:

1. to present and assess a new methodology for the systematic formulation of low-risk drinking guidelines based on country-level lifetime mortality risks;

2. to assess the need for country-specific guidelines by estimating lifetime risks of an alcohol-attributable death in the European countries of Estonia, Finland, Germany, Hungary, Ireland, Italy and Poland (these countries were chosen to represent maximum heterogeneity with respect to drinking cultures and mortality profiles in Europe) (see the appendix and $[8,19])$;

3. to assess the lifetime risk of an alcohol-attributable death for a person drinking the highest average daily alcohol consumption amount allowed by current guidelines; and

4. to assess the proportion of the population in each of the chosen countries that is drinking more alcohol than acceptable risk threshold levels.

\section{Methods}

Cause-of-death data were obtained from the World Health Organization [20]. Mortality data were obtained as the sex- and age-specific number of deaths in 2012, by 163 cause-of-death categorizations (see [20] and supplementary material). Population data were obtained from the United Nations [21]; all such data were obtained by sex and age (in 5-year age groups). Information on current low-risk alcohol drinking guidelines for each examined country was 
obtained from the Joint Action on Reducing Alcohol Related Harm survey [22] and from Ireland's Department of Health, Health Service Executive [23].

Data on alcohol-attributable deaths for 2012 (deaths that would not have occurred under the counterfactual scenario of everyone being a lifetime abstainer) were based on the 2014 Global Status Report on Alcohol and Health (GSRAH) [1]. The appendix provides an overview of the diseases and injuries causally related to alcohol consumption as determined by the 2014 GSRAH [1] and by the Global Burden of Disease Study 2010 [24], except for HIV/AIDS which was not included due to the small number of alcohol-attributable HIV/AIDS deaths in Europe [25]. Furthermore, RRs for these diseases and injuries were obtained from meta-analyses by sex and level of drinking (see appendix). The data sources for RRs were the same as in recent Comparative Risk Assessments [1, 24], except for ischemic heart disease and ischemic stroke which have since been updated ([26] based on [27]). These are the most up-to-date and robust estimates of RRs [1, 24]. Furthermore, these RR functions are similar to other recent metaanalyses, as the majority of the study estimates contained in these meta-analyses are the same [24].

\section{Lifetime risk calculations}

In order to assess the lifetime risk of an alcohol-attributable death under various consumption amounts, the lifetime risk of an alcohol-attributable death was modelled using 1 gram intervals for people who consumed on average 1 to 40 grams (g) of alcohol per day, and using 10 gram 
intervals from 40 to $100 \mathrm{~g} /$ day (see appendix). Risks were calculated for people aged 15-74 years, as in older ages there is considerable misclassification of the cause of death [28-30], and in younger ages alcohol-attributable deaths are rare [1].

The first step in assessing the lifetime risk of an alcohol-attributable death, for each country, was to estimate the absolute age- and country-specific mortality risk for lifetime abstainers on the basis of non-sex-specific mortality and population data for the year 2012 (results using sexspecific mortality are outlined in the supplemental material). For this, the cause-specific alcoholattributable deaths, by age, were subtracted from the overall deaths from that cause. The result of this subtraction was divided by the mid-year population to estimate the cause-specific mortality risk per person per year for a lifetime abstainer. Next, for all modelled consumption amounts (see details in [31]), the RRs (adverse or protective as compared to lifetime abstention) were estimated from a continuous RR function, by cause of death. Thereafter, the cause-specific risk for lifetime abstainers was multiplied by the cause-specific excess RR (the RR minus 1) at each alcohol consumption level (see formula in the appendix). These cause-specific risks were combined to estimate sex- and age-specific mortality risks for an alcohol-attributable death. Lastly, sex- and age-specific alcohol-attributable mortality risks and non-alcohol-attributable mortality risks (competing risk of death) were used to estimate the lifetime risk of an alcohol-attributable death. A more detailed description of the methodology is outlined in the appendix. 
Data on drinking behaviours and alcohol consumed were obtained from the Global Information System on Alcohol and Health (GISAH) [20]. Specifically, these drinking behaviours include the prevalence of current drinkers (those who have consumed at least one standard drink of alcohol in the past year) and current abstainers (those who have not consumed at least one standard drink of alcohol in the past year), as well as the adult per capita consumption of alcohol (PCA) (the amount of alcohol consumed at the population level from recorded, unrecorded and tourist sources (see [20])). The proportion of the population consuming alcohol above various risk thresholds was modelled for the European Union and the 7 individual European countries for 2012 using data from the GISAH according to the methods of Rehm and colleagues using $80 \%$ of PCA $[32,33]$.

\section{Uncertainty estimation}

Uncertainty was calculated by means of Monte Carlo methodology with 40,000 simulations of the lowest level parameters [34]. The 2.5 and 97.5 percentiles of each sex-, country- and alcohol consumption-specific lifetime mortality risk simulated distribution were used as approximations for $95 \%$ confidence intervals $(\mathrm{CI})$.

\section{Definition of acceptable risk}

An acceptable level of risk tends to be defined differently for voluntary behaviours (such as alcohol drinking, smoking, etc. [35]) compared to risks from involuntary exposures (e.g., air pollution [36-38]); (for background of the distinction between voluntary and involuntary risk, see 
[35, 39-41]). The conclusion of Starr's analysis (see [35] p. 1237) can be used to estimate acceptable voluntary risk, namely that the public is willing to accept "voluntary" risks roughly 1,000 times greater than "involuntary" risks (see [35] and [8]).

A one in one million lifetime mortality risk has become somewhat of a gold standard of acceptable risk for involuntary exposure, and has been used in different areas such as water safety in Australia and the US [36, 37] and for increases in exposure to carcinogens in air, sediment or soil [38]. Dividing this risk by 1,000 (the ratio from Starr (see [35]) for acceptable levels of involuntary versus voluntary risk) leads to a maximum acceptable voluntary risk of 1 in 1,000 [35]. However, it should be noted that other definitions of acceptable voluntary risk have been used [38]. For the Australian guidelines [11] and the UK guidelines [12], implicitly a standard of 1 in 100 was used, which standard we used for sensitivity analyses.

\section{Results}

If in 2012 all people consumed alcohol at current country-specific guideline thresholds, we would have observed for men an estimated range in the alcohol-attributable lifetime premature mortality risk of 2.5 deaths per 1,000 in Finland (maximum of $20 \mathrm{~g} /$ day) to 44.8 deaths per 1,000 in Estonia (maximum of $40 \mathrm{~g} /$ day) (see Table 1). For women, we would have observed an estimated range in the alcohol-attributable lifetime premature mortality risk of 2.9 deaths per 1,000 in Finland (maximum of $10 \mathrm{~g} /$ day) to 35.8 deaths per 1,000 in Estonia (maximum of $20 \mathrm{~g} /$ day). The amount of alcohol that leads to the lowest alcohol-attributable premature mortality risk is outlined in the 
supplemental material. The alcohol-attributable lifetime premature mortality risks at maximum consumption levels within the current alcohol drinking guidelines are greater than 1 in 1,000 for all countries examined. Furthermore, Poland and Estonia had alcohol-attributable lifetime premature mortality risks above 1 in 100 under current guideline maximums.

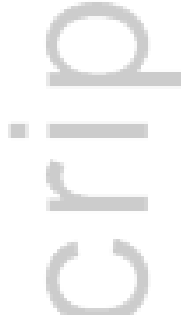

< Insert Table 1 about here >

Figure 1 outlines the lifetime risk of an alcohol-attributable death up to 74 years of age for various levels of alcohol consumption. Among men, alcohol consumption of $10 \mathrm{~g} /$ day over a lifetime was associated with a protective rather than a detrimental effect in most investigated countries (only Estonian men experienced a detrimental effect at $10 \mathrm{~g} /$ day). In contrast, among women, consuming $10 \mathrm{~g} /$ day was protective in only one country (Poland) and was detrimental in the remaining countries.

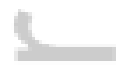

< Insert Figure 1 about here >

At lower levels of alcohol consumption, the alcohol-attributable lifetime premature mortality risk did not vary appreciably by country. Women who consumed $10 \mathrm{~g} /$ day had a risk higher than the risk threshold of 1 in 1,000 in Estonia, Finland, Italy and Germany, and women who consumed $20 \mathrm{~g} /$ day had a risk higher than this threshold in all countries examined. For men, those who consumed $10 \mathrm{~g} /$ day in Estonia had a risk higher than this threshold, and those who consumed 20 
$\mathrm{g}$ /day had a risk higher than this threshold in all other countries, except for Poland, where men who consumed $30 \mathrm{~g} /$ day had a risk higher than this threshold.

At higher levels of alcohol consumption, the alcohol-attributable lifetime premature mortality risk varied appreciably by country. Estonia had the highest alcohol-attributable lifetime premature mortality risk at all levels of alcohol consumption for both men and women, while Italy had the lowest alcohol-attributable lifetime premature mortality risk for both men and women at all levels of alcohol consumption. At the highest level of consumption examined (100 g/day), for men, the alcohol-attributable lifetime premature mortality risk ranged from 88.7 per 1,000 (95\% CI: 67.6 to 100.7 ) in Italy to 237.4 per 1,000 (95\% CI: 201.8 to 272.0 ) in Estonia. For a woman who consumed on average $100 \mathrm{~g} /$ day, the alcohol-attributable lifetime premature mortality risk ranged from 172.6 per 1,000 (95\% CI: 138.8 to 216.5 ) in Italy to 526.2 per 1,000 (95\% CI: 444.7 to 652.0 ) in Estonia. This can be attributed to the different underlying agespecific risks of death from causes that are causally related to alcohol consumption in these countries [42], such as cardiovascular diseases and cancer which are also impacted by other risk factors such as tobacco and obesity [43], and injuries which are affected by injury prevention efforts [44], and differences in the age-specific risks of competing causes of death.

With the assumption that there is the same level of risk for male and female non-drinkers, the same level of alcohol consumption leads to higher absolute mortality risks for women than for 
men in all countries examined. This reflects the higher RRs given the same level of alcohol consumption for women compared to men for almost any alcohol-related disease or injury.

Table 2 outlines the prevalence of people, differentiated by sex, who consumed 10, 20, 30, 60 and $100 \mathrm{~g} /$ day, resulting in a lifetime premature mortality risk above 1 in 1,000. A large proportion of the adult population in the examined countries drank amounts of alcohol above the mortality risk limit of 1 in 1,000 . For women, this proportion ranged from $20.6 \%$ of the population in Poland to $32.9 \%$ of the population in Germany, while for men, this proportion ranged from $35.4 \%$ of the population in Italy to $54.0 \%$ of the population in Estonia. Furthermore, in the European Union, $2.6 \%$ of all adult women (3.7\% of all adult female drinkers) and $13.7 \%$ of all adult men (19.2\% of all adult male drinkers) consumed on average more than $60 \mathrm{~g} / \mathrm{day}$, and thus were chronic heavy drinkers.

< Insert Table 2 about here >

\section{Discussion}

If based on a maximum voluntary lifetime premature mortality risk of 1 in 1,000, guidelines for Europe should indicate that alcohol consumption should not exceed 7 to $13 \mathrm{~g} /$ day for women and 7 to $20 \mathrm{~g}$ /day for men. Even using a risk of 1 in 100, alcohol consumption should not exceed 11 to $19 \mathrm{~g} /$ day for women and 17 to $34 \mathrm{~g} /$ day for men. Secondly, coupling alcohol consumption data with lifetime risk estimates indicates that a large proportion of the examined populations drank at 
risky levels. Thirdly, although the risks at high levels of consumption differed between countries, there was much less variation in these risks at levels relevant for setting low-risk guidelines.

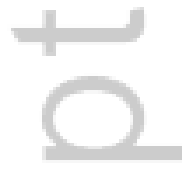

< Insert Box 1 about here >

This is the first study to systematically determine thresholds for low-risk alcohol consumption by accounting for competing risks and using an acceptable maximum premature mortality risk threshold used for other risks. The lifetime risk method is easier to understand and clearer to communicate [45], uses established thresholds for acceptable lifetime premature mortality risks $[8,46]$ which can be changed if there is social consensus, and allows for a comparison of lifetime mortality risk from alcohol consumption with other risk factors. As indicated above, there may be other standards used for involuntary risk, both more or less strict (see above and [47]). The chosen threshold of 1 in 1,000 would be in line with recommendations for food with respect to carcinogenicity [48], or with the considerations of the UK Health and Safety Executive ([47], pp. 44ff.). One way to escape the arbitrariness of thresholds would be for international organizations such as the World Health Organization or the United Nations to establish a single standard for all behavioural risk factors [49].

\section{Limitations}

Our study is subject to limitations. Firstly, the reported risks are based on average consumption, and not on drinks consumed per drinking occasion. For instance, for persons engaged in heavy 
episodic drinking (consuming $\geq 60 \mathrm{~g}$ on at least one occasion monthly), there is no protective effect of alcohol consumption on ischemic cardiovascular diseases [50, 51]. Furthermore, drinking patterns affect the risk of injury, whereby the risk of injury is lower for people who consume a consistent amount of alcohol over many days than for people who consume the same amount on fewer occasions (this mortality risk due to drinking patterns may also be different by country due to differences in, for example, road safety [1]). In this sense, the current calculations may be conservative, and taking into account drinking patterns would lead to lower average guidelines, as the alcohol-attributable mortality risk decreases at average moderate drinking levels, the more that the same amount of alcohol consumed is spread out over time, i.e., the lower the variance, and the more similar the drinking patterns are over time [52].

Secondly, statistical models are only as good as their input. The RRs were obtained from metaanalyses, which have been based on studies where participants may have underestimated their drinking, likely leading to higher guidelines. Unfortunately, while there is literature on the average level of underestimation of general population surveys $[53,54]$, the coverage rate of epidemiological studies is not that clear, as different methods of assessment yield different results [55], and the gold standard is not clear, since sales or other administrative statistics for specific groups of people are not available. The use of food frequency questionnaires in more medical epidemiology settings may yield different results, as those questionnaires have been successfully validated and have yielded higher average consumption levels in experimental research [55-58]. Furthermore, the underlying RRs upon which the meta-analyses are based use lifetime abstainers 
as a reference category which leads to various biases [59], including a proportion of former drinkers being misclassified as lifetime abstainers leading to an underestimation of the RRs [60]. Lastly, as previously mentioned, the underlying cohort studies upon which the RRs are in part based typically follow middle-class participants who are middle aged, and, thus, the causespecific RRs from these studies may not apply to other segments of the general population [13, 14].

Thirdly, as with all other guidelines, alcohol-attributable health harms to others (such as low birth weight [61], traffic injuries [9], and violence [62]) were not accounted for, as guidelines are intended to inform drinkers about risks to themselves. Furthermore, this study was limited to alcohol's impact on mortality, and did not include (i) risk tolerance differences between countries and cultures [63], (ii) alcohol's impact on society, the economy, or morbidity, or (iii) the pleasure that people may obtain from drinking (an internal measure, which has been shown to be hard to quantify [64]), as guidelines for risk factors are currently set based on mortality alone [1].

Lastly, cohort studies have observed that women have a higher risk of death per gram of pure alcohol consumed even at smaller amounts when compared to men [65]. However, men have a higher overall risk of death from all causes when compared to women. Therefore, if the underlying risk of death for men and for women were not combined, we would obtain estimates of the risk of an alcohol-attributable death by sex that are low for women when compared with results observed in cohort studies (although there is a bias in cohort studies towards certain 
causes of death when compared to the general population) [66-68]. To lessen the differences between the lifetime risk of an alcohol-attributable death reported in this paper and the sexspecific risks of alcohol-attributable death obtained from observational studies, we performed an analysis combining the age and cause-specific risk of death by sex.

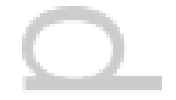

To address these limitations, cause-specific mortality studies are needed which address the effects of patterns as well as levels of drinking. Such studies will allow improved estimation of low-risk thresholds for consumption per drinking occasion.

Research is also needed on the health risks to others than the drinker, as such risks have been observed to be substantial [69]; for instance, in Australia in 2008, 387 deaths and 14,000 hospitalizations occurred due to the drinking of others, representing a mortality risk higher than 1 in 1,000 deaths and a hospitalization risk of 0.5 in 1,000 [69]. In this light, there would be substantial justification on public health grounds for drinking guidelines to be based on an involuntary risk standard (one in one million). Such guidelines would be well below consumption of $10 \mathrm{~g} /$ day [8].

\section{Comparison to previous studies}

This study's methodology represents an improvement when compared to previous analyses. The majority of guidelines have been based on all-cause alcohol RR curves. The use of these RRs should be avoided, as their generalizability is limited since there are marked differences in cause- 
of-death structures across countries and time [49], and because the cohorts are often selected for the ease of follow-up rather than to be representative [70]. The Australian low-risk drinking guidelines (and the UK drinking guidelines which were based on the Australian methodology) used a different approach $[11,71]$. The low-risk alcohol consumption threshold of the Australian guidelines was formulated using a lifetime risk approach [11], based on risks disaggregated by sex and cause of death. However, the Australian guidelines have limitations compared to this study. Firstly, the guidelines do not include the protective effects of alcohol, as the existence of these effects was controversial [11] (the UK guidelines added in the protective effects of alcohol [71]). Secondly, the guidelines are based on the now out-of-date 2004 Comparative Risk Assessment study methodology [72]. Thirdly, the lifetime risk was calculated by summing alcohol-attributable mortality risk across age groups, and therefore did not account for the risk of dying from competing causes of death. However, the methodology of the Australian and UK guidelines does produce estimates of low-risk consumption which are in line with our findings $[11,71]$

The methodology presented in this manuscript overcomes weaknesses in previous methodologies by using a lifetime risk approach based on acceptable limits used for other behavioural risks, accounting for competing risks, and including the protective effects of alcohol. The findings of this study indicate that current thresholds for low-risk drinking guidelines are higher than what is considered acceptable for other consumptive behaviours, and confirm observations that alcohol is commonly consumed in Europe at risky levels [73]. 


\section{Clinical and public health applications}

The findings of this study have multiple clinical and public health applications. The limited variation in the lifetime risk of an alcohol-attributable death between European countries at levels relevant for setting alcohol drinking guidelines suggests that a common threshold for low-risk drinking in Europe is appropriate - for instance at 7-13 g/day for women and 7-20 g/day for men - which would keep the lifetime risk of an alcohol-related death either below or close to 1 in 1,000. Such agreement would inform policy decisions regarding screening for alcohol abuse and/or dependence and for health information printed on labels of alcoholic beverage containers. However, other avenues used to decrease alcohol's harms, such as taxation increases and availability restrictions, should also be implemented [74]. Low-risk guidelines are a potential educational and persuasive tool, but are only a single element of effective policies to reduce harms from hazardous alcohol consumption [8].

\section{Conclusions}

If drinking guidelines are based on a threshold of 1 in 1,000 as an acceptable mortality risk from behavioural risk factors, then most current guidelines in most European countries are in need of downward revision. Taking into consideration the harms to others caused by alcohol, this situation is further exacerbated. Revising the levels defined as low-risk consumption based on scientific evidence and making explicit the considerations underpinning the definition would best fulfill the central objective of drinking guidelines: to offer evidence-based guidance to the 
citizenry on risk levels for a voluntary behaviour, which they can then balance against what they find positive about drinking in making decisions about their consumption levels.

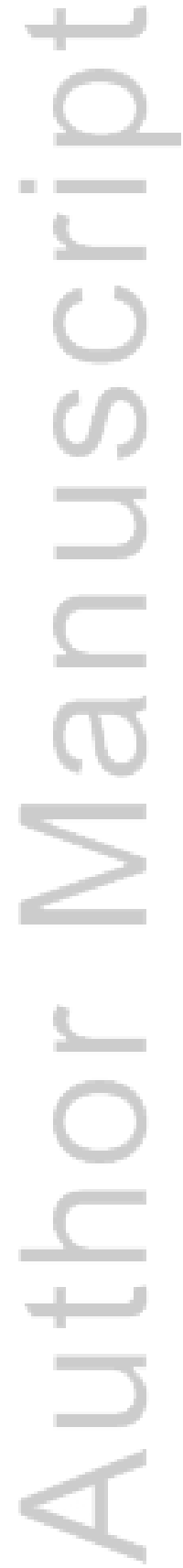




\section{Funding}

This work was supported by the National Institute for Health and Welfare, Finland, in the framework of the Joint Action on Reducing Alcohol Related Harm (RARHA), co-funded by the European Union Health Programme (2008-2013). The research leading to these results or outcomes was supported by the European Community's Seventh Framework Programme (FP7/2007-2013) [grant number 266813] - Addictions and Lifestyle in Contemporary Europe Reframing Addictions Project (ALICE RAP - www.alicerap.eu). Participant organizations in ALICE RAP can be seen at http://www.alicerap.eu/about-alice-rap/partner-institutions.html.

\section{Acknowledgements}

The authors would like to thank Michelle Tortolo for referencing the manuscript. The authors would also like to thank Drs. Dirk Lachenmeier, Marjatta Montonen, Esa Österberg and Michael Roerecke for their respective comments on earlier versions of this paper.

The content of this report represents the views of the authors and is their sole responsibility; it can in no way be taken to reflect the views of the European Commission and/or the Consumer, Health and Food Executive Agency or any other body of the European Union. The European Commission and/or the Executive Agency do not accept responsibility, and are not liable, for any use that may be made of the information this report contains.

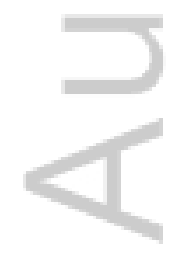




\section{Completing interests}

None declared

\section{Ethics approval}

Ethics approval was not required, as this study involved secondary data analyses only.

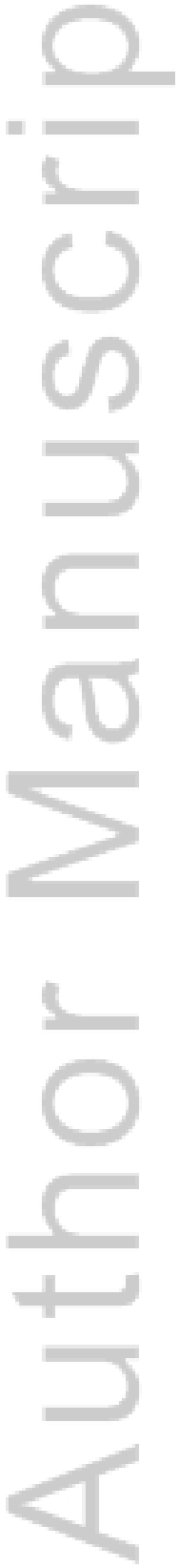

This article is protected by copyright. All rights reserved. 


\section{Figures, tables and boxes}

Box 1. Key messages of the study

Figure 1. Lifetime risk (up to 74 years of age) of an alcohol-attributable death for men and women in (A) Estonia, (B) Finland, (C) Germany, (D) Hungary, (E) Ireland, (F) Italy, and (G) Poland for different average daily alcohol consumption volumes

Table 1. Current country guidelines for low-risk average alcohol consumption amounts, risk of death under these guidelines, and average alcohol consumption limits based on an acceptable lifetime risk of 1 in 1,000 people and 1 in 100 people

Table 2. Prevalence of average daily alcohol intake for adult (15 years of age and older) women and men in 2012 in the European Union and in various European countries

\section{Appendices}

Supplemental material

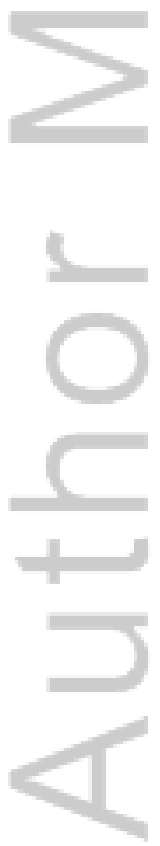


Box 1. Key messages of the study

- A lifetime risk approach is presented for estimating alcohol-attributable deaths in seven European countries, taking into consideration competing risks.

- If drinking guidelines are based on the common thresholds for an acceptable lifetime mortality risk for other behavioural risk factors (i.e., 1 in 1,000), then most current European low-risk guideline maximums should be revised downward to 8 to $10 \mathrm{~g} /$ day for women and 15 to $20 \mathrm{~g} /$ day for men.

- Revising guideline thresholds for low-risk consumption downward based on scientific evidence of lifetime risk, as well as making the underpinning considerations explicit, would bring the manner in which alcohol risks are regarded in line with other behavioural risk factors.

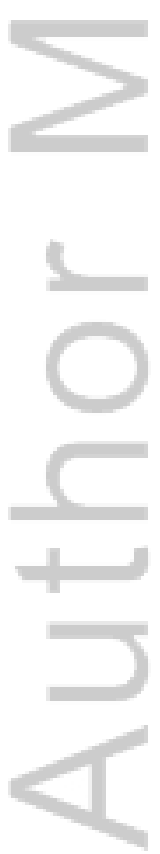


Table 1. Current country guidelines for low-risk average alcohol consumption amounts, risk of death under these guidelines, and average alcohol consumption limits based on an acceptable lifetime risk of 1 in 1,000 people and 1 in 100 people

\begin{tabular}{|c|c|c|c|c|}
\hline Country & $\begin{array}{l}\text { Current guidelines on average } \\
\text { daily consumption not to } \\
\text { exceed (g/day) }\end{array}$ & $\begin{array}{l}\text { Lifetime risk of death at } \\
\text { guideline maximum (per } \\
1,000 \text { people) }\end{array}$ & $\begin{array}{c}\text { Alcohol consumption (g/day) } \\
\text { where lifetime risk of death } \\
\text { equals } 1 \text { in } 100\end{array}$ & $\begin{array}{c}\text { Alcohol consumption (g/day) } \\
\text { where lifetime risk of death } \\
\text { equals } 1 \text { in } 1,000\end{array}$ \\
\hline \multirow[t]{7}{*}{ Men } & 40 & 44.8 & 17 & 7 \\
\hline & 20 & 2.5 & 31 & 16 \\
\hline & 24 & 5.7 & 30 & 14 \\
\hline & Range (24 - 28) & $(7.6-12.4)$ & 26 & 17 \\
\hline & $24.3^{*}$ & 4.2 & 34 & 17 \\
\hline & 24 & 5.7 & 31 & 13 \\
\hline & 40 & 22.6 & 30 & 20 \\
\hline Women Estonia & 20 & 35.8 & 11 & 7 \\
\hline Finland & 10 & 2.9 & 15 & 7 \\
\hline Germany & 12 & 3.7 & 17 & 8 \\
\hline Hungary & Range (18-21) & $(18.9-27.6)$ & 14 & 10 \\
\hline Ireland & $15.7^{*}$ & 6.0 & 19 & 10 \\
\hline
\end{tabular}

This article is protected by copyright. All rights reserved. 


\begin{tabular}{llccc} 
Italy & & & & \\
Poland & 12 & 3.1 & 18 & 18 \\
\hline
\end{tabular}

* Up to 11 standard drinks among men and 17 standard drinks among women per week (1)
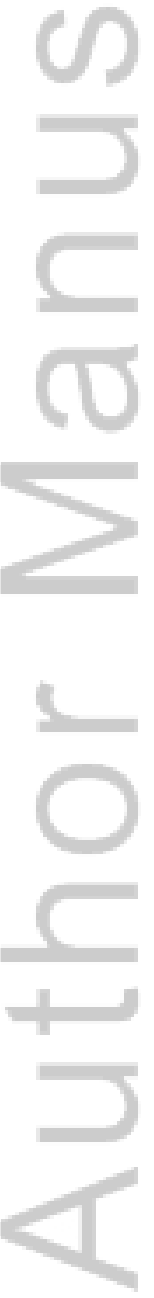

This article is protected by copyright. All rights reserved. 
Table 2. Prevalence of average daily alcohol intake for adult (15 years of age and older) women and men in 2012 in the European Union and in various European countries

\begin{tabular}{|c|c|c|c|c|c|c|c|c|}
\hline Sex & Country & $\begin{array}{l}\mathrm{g} / \text { day that } \\
\text { result in a } \\
\text { lifetime } \\
\text { risk above } \\
1 \text { in } 1,000\end{array}$ & $\begin{array}{l}>\mathrm{g} / \mathrm{day} \text { that } \\
\text { result in a } \\
\text { lifetime risk } \\
\text { above } 1 \text { in } \\
1,000\end{array}$ & $\begin{array}{l}\geq \quad 10 \\
\text { g/day }\end{array}$ & $\begin{array}{l}\geq \quad 20 \\
\text { g/day }\end{array}$ & $\begin{array}{l}\geq \quad 30 \\
\text { g/day }\end{array}$ & $\begin{array}{l}\geq \quad 60 \\
\text { g/day }\end{array}$ & $\begin{array}{l}\geq \\
100 \\
\text { g/day }\end{array}$ \\
\hline & Estonia & 7 & $31.7 \%$ & $26.3 \%$ & $15.1 \%$ & $9.2 \%$ & $2.4 \%$ & $0.5 \%$ \\
\hline & Finland & 7 & $37.6 \%$ & $32.1 \%$ & $20.2 \%$ & $13.2 \%$ & $4.2 \%$ & $1.0 \%$ \\
\hline & Germany & 8 & $39.2 \%$ & $34.7 \%$ & $19.8 \%$ & $11.9 \%$ & $3.0 \%$ & $0.5 \%$ \\
\hline & Hungary & 10 & $33.1 \%$ & $33.1 \%$ & $19.2 \%$ & $11.7 \%$ & $3.0 \%$ & $0.5 \%$ \\
\hline \multirow{5}{*}{ Wom } & Ireland & 10 & $32.1 \%$ & $32.1 \%$ & $17.5 \%$ & $10.0 \%$ & $2.2 \%$ & $0.3 \%$ \\
\hline & Italy & 9 & $21.0 \%$ & $19.3 \%$ & $8.7 \%$ & $4.2 \%$ & $0.6 \%$ & $0.1 \%$ \\
\hline & Poland & 13 & $20.6 \%$ & $23.5 \%$ & $15.4 \%$ & $10.5 \%$ & $3.6 \%$ & $1.0 \%$ \\
\hline & $\begin{array}{l}\text { European } \\
\text { Union }\end{array}$ & - & - & $30.8 \%$ & $17.4 \%$ & $10.4 \%$ & $2.6 \%$ & $0.5 \%$ \\
\hline & Estonia & 7 & $54.0 \%$ & $49.5 \%$ & $38.1 \%$ & $30.0 \%$ & $15.3 \%$ & $6.6 \%$ \\
\hline \multirow{6}{*}{ Men } & Finland & 16 & $44.3 \%$ & $52.1 \%$ & $40.0 \%$ & $31.4 \%$ & $16.0 \%$ & $6.8 \%$ \\
\hline & Germany & 14 & $49.2 \%$ & $55.5 \%$ & $41.5 \%$ & $31.7 \%$ & $15.0 \%$ & $5.8 \%$ \\
\hline & Hungary & 17 & $49.1 \%$ & $59.3 \%$ & $45.4 \%$ & $35.5 \%$ & $18.0 \%$ & $7.7 \%$ \\
\hline & Ireland & 17 & $42.7 \%$ & $54.2 \%$ & $38.8 \%$ & $28.4 \%$ & $11.9 \%$ & $4.0 \%$ \\
\hline & Italy & 13 & $35.4 \%$ & $41.6 \%$ & $24.7 \%$ & $15.2 \%$ & $3.9 \%$ & $0.7 \%$ \\
\hline & Poland & 20 & $37.8 \%$ & $46.9 \%$ & $37.8 \%$ & $31.1 \%$ & $18.0 \%$ & $9.1 \%$ \\
\hline & $\begin{array}{l}\text { European } \\
\text { Union }\end{array}$ & - & - & $53.4 \%$ & $39.1 \%$ & $29.5 \%$ & $13.7 \%$ & $5.4 \%$ \\
\hline
\end{tabular}

This article is protected by copyright. All rights reserved. 


\section{Reference List}

1. World HeALTH ORgANizATION (2014) Global status report on alcohol and health (Geneva, Switzerland, World Health Organization).

2. Rehm, J., Mathers, C., Popova, S., Thavorncharoensap, M., Teerawattananon, Y. \& Patra, J. (2009) Global burden of disease and injury and economic cost attributable to alcohol use and alcohol use disorders, Lancet, 373, 2223-2233.

3. Forouzanfar, M. H.AleXander, L.Anderson, H. R.BAChman, V. F.Biryukov, S.Brauer, M. et al. (2015) Global, regional, and national comparative risk assessment of 79 behavioural, environmental and occupational, and metabolic risks or clusters of risks in 188 countries, 1990-2013: a systematic analysis for the Global Burden of Disease Study 2013, Lancet, 386, 2287-323.

4. GBD 2015 RISK FACTORS COLLABORATORS (2016) Global, regional, and national comparative risk assessment of 79 behavioral, environmental and occupational, and metabolic risks or clusters of risks, 1990-2015: a systematic analysis for the Global Burden of Disease Study 2015, Lancet 388, 1659-1724.

5. ROOM, R. \& REHM, J. (2012) Clear criteria based on absolute risk: reforming the basis of guidelines on low-risk drinking, Drug and Alcohol Review, 31, 135-140.

6. STOCKLEY, C. S. (2007) Recommendations on alcohol consumption: an international comparison, Contemporary Drug Problems, 34, 681-714.

7. Rehm, J., Baliunas, D., Borges, G. L., Graham, K., IRVING, H. M., KeHOE, T. et al. (2010) The relation between different dimensions of alcohol consumption and burden of disease An overview, Addiction, 105, 817-843.

8. ReHM, J., LACHENMEIER, D. W. \& ROOM, R. (2014) Why does society accept a higher risk for alcohol than for other voluntary or involuntary risks?, BMC Medicine, 12, 189.

9. HURST, P., HARTE, W. \& FIRTH, W. (1994) The Grand Rapids dip revisited, Accident Analysis and Prevention, 26, 647-654.

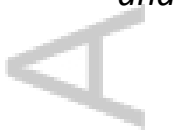

This article is protected by copyright. All rights reserved. 
10. REHM, J., ROOM, R. \& TAYLOR, B. (2008) Method for moderation: measuring lifetime risk of alcohol-attributable mortality as a basis for drinking guidelines, International Journal of Methods in Psychiatric Research, 17, 141-151.

11. National Health and Medical Research Council (2009) Australian guidelines to reduce health risks from drinking alcohol (Canberra, Australia, Commonwealth of Australia).

12. National Health and Medical Research Council (2016) Alcohol Guidelines Review - Report from the Guidelines development group to the UK Chief Medical Officers (London, United Kingdom: Department of Health).

13. REHM, J. (2000) Alcohol consumption and mortality. What do we know and where should we go?, Addiction, 95, 989-995.

14. REHM, J., GMEL, G., SEMPOS, C. \& TREVISAN, M. (2003) Alcohol-related mortality and morbidity, Alcohol Research \& Health, 27, 39-51.

15. Roerecke, M., Shield, K. D., Higuchi, S., Yoshimura, A., Larsen, E., Rehm, M. X. et al. (2015) Estimates of alcohol-related oesophageal cancer burden in Japan: systematic review and meta-analyses, Bulletin of the World Health Organization, 93, 329-338c.

16. Brooks, P. J., ENOCh, M. A., Goldman, D., LI, T. K. \& YokoyamA, A. (2009) The alcohol flushing response: an unrecognized risk factor for esophageal cancer from alcohol Consumption, PLoS Medicine, 6, 258-263.

17. Kuper, H., Tzonou, A., Kaklamani, E., Hsieh, C. C., Lagiou, P., Adami, H. O. et al. (2000) Tobacco smoking, alcohol consumption and their interaction in the causation of hepatocellular carcinoma, International Journal of Cancer, 85, 498-502.

18. LIEBER, C. S. (1990) Interaction of alcohol with other drugs and nutrients, Drugs, 40, 2344.

19. Popova, S., ReHM, J., PATRA, J. \& ZATONSKI, W. (2007) Comparing alcohol consumption in central and eastern Europe to other European countries, Alcohol and Alcoholism, 42, 465-473.

20. World HeALTH ORgANizATION (2015) Global Health Observatory: mortality and global health estimates (Geneva, Switzerland: World health Organization).

This article is protected by copyright. All rights reserved. 
21. United NAtions (2013) World Population Prospects: The 2012 Revision (New York, USA, United Nations).

22. Scafato, E., Galluzzo, L., Ghirini, S. \& Gandin, C. (2014) Where do EU Countries set the limit for low risk drinking. Results from the EU RARHA survey 6th European Alcohol policy conference (Brussels, Belgium). Archived by WebCite ${ }^{\circledR}$ at http://www.webcitation.org/6IHTbxoYg (accessed 15 October 2016)

23. Health Services EXeCUtive (2017) Alcohol Programme (Health Services Executive; Dublin, Ireland).

24. Lim, S. S.Vos, T.FlaXman, A. D.Danael, G.Shibuya, K.AdaiR-Rohani, H. et al. (2012) A comparative risk assessment of burden of disease and injury attributable to 67 risk factors and risk factor clusters in 21 regions, 1990-2010: a systematic analysis for the Global Burden of Disease Study 2010 Lancet 380, 2224-2260.

25. GMEL, G., SHIELD, K. \& REHM, J. (2011) Developing a methodology to derive alcoholattributable fractions for HIV/AIDS mortality based on alcohol's impact on adherence to antiretroviral medication, Population Health Metrics, 9, 5.

26. ReHM, J., ShieLd, K. D., RoereCKe, M. \& GMeL, G. (2014) Modelling the impact of alcohol consumption on cardiovascular disease mortality for comparative risk assessments: an overview (Toronto, Canada, Centre for Addiction and Mental Health).

27. ROERECKE, M. \& REHM, J. (2014) Alcohol consumption, drinking patterns, and ischemic heart disease: a narrative review of meta-analyses and a systematic review and metaanalysis of the impact of heavy drinking occasions on risk for moderate drinkers, $B M C$ Medicine, 12, 182.

28. ColemAN, M. P. \& AYLIN, P. (2000) Death certification and mortality statistics: an international perspective (Studies on medical and population subjects \# 64) (London, UK, The Stationary Office).

29. HARTELOH, P., DE BRUIN, K. \& KARDAUN, J. (2010) The reliability of cause-of-death coding in the Netherlands, European Journal of Epidemiology, 25, 531-538.

This article is protected by copyright. All rights reserved. 
30. Alpérovitch, A., Bertrand, M., Jougla, E., Vidal, J. S., Ducimetière, P. \& Helmer, C. (2009) Do we really know the cause of death of the very old? Comparison between official mortality statistics and cohort study classification, European Journal of Epidemiology, 24, 669-675.

31. REHM, J., GMEL, G., PROBST, C. \& SHIELD, K. D. (2015) Lifetime-risk of alcohol-attributable mortality based on different levels of alcohol consumption in seven European countries. Implications for low-risk drinking guidelines (Toronto, Canada, Centre for Addiction and Mental Health).

32. Rehm, J., KehOE, T., GMel, G., Stinson, F., Grant, B. \& GMEL, G. (2010) Statistical modeling of volume of alcohol exposure for epidemiological studies of population health: the example of the US, Population Health Metrics, 8, 3.

33. KeHOE, T., GMeL, G., JR., SHIELD, K., GMEL, G., SR. \& ReHM, J. (2012) Determining the best population-level alcohol consumption model and its impact on estimates of alcoholattributable harms, Population Health Metrics 10, 6.

34. Gmel, G. J., Shield, K. D., Frick, H., Kehoe, T., GMel, G. \& Rehm, J. (2011) Estimating uncertainty of alcohol-attributable fractions for infectious and chronic diseases, $B M C$ Medical Research Methodology, 11, 48.

35. StARR, C. (1969) Social benefit versus technological risk, Science, 165, 1232-1238.

36. National Health Medical Research Council (2004) Australian drinking water guidelines, Canberra: National Health and Medical Research Council (Canberra, Australia, National Health and Medical Research Council).

37. Hunter, P. R. \& FeWTRelL, L. (2001) Acceptable risk, in: Fewtrel, L. \& Bartram, J. (Eds.) Water quality: guidelines, standards and health, pp. 207-227 (London, UK, IWA Publishing).

38. RIFKIN, E. \& BOUWER, E. (2007) The Illusion of Certainty: Health Benefits and Risks (New York, USA, Springer).

39. Kahneman, D. (2011) Thinking Fast and Slow (New York, Farrar, Straus and Giroux).

This article is protected by copyright. All rights reserved. 
40. Fischinoff, B., Lichtenstein, S., Slovic, P., Derby, S. L. \& Keeney, R. L. (1981) Acceptable risk (Cambridge, UK, Cambridge University Press).

41. SLOVIC, P. (1987) Perception of Risk, Science, 236, 280-285.

42. GBD 2015 Mortality AND CAUSES Of DeAth Collaborators (2016) Global, regional, and national life expectancy, all-cause mortality, and cause-specific mortality for 249 causes of death, 1980-2015: a systematic analysis for the Global Burden of Disease Study 2015, Lancet, 388, 1459-1544.

43. Mokdad, A. H., Forouzanfar, M. H., Daoud, F., Mokdad, A. A., El Bcheraoul, C., MoradiLAKEH, M. et al. (2016) Global burden of diseases, injuries, and risk factors for young people's health during 1990-2013: a systematic analysis for the Global Burden of Disease Study 2013, Lancet, 387, 2383-2401.

44. HaAgsma, J. A., Graetz, N., Bolliger, I., Naghavi, M., Higashi, H., Mullany, E. C. et al. (2016) The global burden of injury: incidence, mortality, disability-adjusted life years and time trends from the Global Burden of Disease study 2013, Injury Prevention, 22, 3-18.

45. Gigerenzer, G. (2013) Risk Savvy: How to Make Good Decisions (New York, USA, Penguin).

46. Blastland, M. \& SpiegelHalter, D. (2013) The Norm chronicles. Stories and number about risk (London, UK, Profile).

47. Health \& SAFETy EXECUTIVE (2001) Reducing risks, protecting people: HSE's decisionmaking process (Norwich, UK, Crown).

48. Lachenmeier, D. W., Przybylski, M. C. \& Rehm, J. (2012) Comparative risk assessment of carcinogens in alcoholic beverages using the margin of exposure approach, International Journal of Cancer, 131, E995-E1003.

49. REHM, J. \& PATRA, J. (2012) Different guidelines for different countries? On the scientific basis of low-risk drinking guidelines and their implications, Drug and Alcohol Review, 31, 156-161.

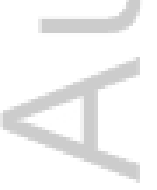

This article is protected by copyright. All rights reserved. 
50. RoERECKE, M. \& ReHM, J. (2010) Irregular heavy drinking occasions and risk of ischemic heart disease: a systematic review and meta-analysis, American Journal of Epidemiology, $171,633-644$.

51. Sundell, L., SalomaA, V., Vartiainen, E., Poikolainen, K. \& LaAtikainen, T. (2008) Increased stroke risk is related to a binge drinking habit, Stroke, 39, 3179-3184.

52. WaLSH, G. \& ReHM, J. (1996) Daily drinking and harm, Contemporary Drug Problems, 23, 465-478.

53. MIDANIK, L. T. (1982) The validity of self-reported alcohol consumption and alcohol problems: a literature review, British Journal of Addiction, 77, 357-382.

54. REHM, J., KLOTSCHE, J. \& PATRA, J. (2007) Comparative quantification of alcohol exposure as risk factor for global burden of disease, International Journal of Methods in Psychiatric Research, 16, 66-76.

55. KING, A. C. (1994) Enhancing the self-report of alcohol consumption in the community: two questionnaire formats, American Journal of Public Health, 84, 294-296.

56. WILLETT, W. (2012) Nutritional epidemiology (Oxford, UK, Oxford University Press).

57. Giovannucci, E., Colditz, G., StAMPfer, M. J., Rimm, E. B., Litin, L., SAMPSON, L. et al. (1991) The assessment of alcohol consumption by a simple self-administered questionnaire, American Journal of Epidemiology, 133, 810-817.

58. REHM, J. (1998) Measuring quantity, frequency and volume of drinking, Alcoholism: Clinical \& Experimental Research, 22, 4S-14S.

59. Rehm, J., IRVING, H., Ye, Y., KerR, W. C., Bond, J. \& Greenfield, T. K. (2008) Are lifetime abstainers the best control group in alcohol epidemiology? On the stability and validity of reported lifetime abstention, American Journal of Epidemiology, 168, 866-871.

60. ZeISSER, C., STOCKWELL, T. R. \& CHIKRITZHS, T. (2014) Methodological biases in estimating the relationship between alcohol consumption and breast cancer: the role of drinker misclassification errors in meta-analytic results, Alcoholism: Clinical \& Experimental Research, 38, 2297-2306.

This article is protected by copyright. All rights reserved. 
61. Patra, J., Bakker, R., IRVIng, H., Jaddoe, V. W. V., MalinI, S. \& Rehm, J. (2011) Doseresponse relationship between alcohol consumption before and during pregnancy and the risks of low birthweight, preterm birth and small for gestational age (SGA)-a systematic review and meta-analyses, International Journal of Obstetrics and Gynaecology, 118, 1411-1421.

62. Evans, C. M. (1980) Alcohol, violence and aggression, Alcohol and Alcoholism, 15, 104117.

63. WeBER, E. U. \& HSEE, C. (1998) Cross-cultural differences in risk perception, but crosscultural similarities in attitudes towards perceived risk, Management science,, 44, 12051217.

64. Johansson, P., Jarl, J., ERIKSSON, A., ERIKSSON, M., Gerdtham, U., HeMSTRÖm, Ö. et al. (2006) The social costs of alcohol in Sweden 2002 (Stockholm, Sweden, SoRADs Stockholm University)

65. Shield, K. D., PARry, C. \& Rehm, J. (2013) Focus on: Chronic diseases and conditions related to alcohol use, Alcohol Research 85, 2.

66. Gaziano, J. M., Gaziano, T. A., Glynn, R. J., Sesso, H. D., Ajani, U. A., Stampfer, M. J. et al. (2000) Light-to-moderate alcohol consumption and mortality in the Physicians' Health Study enrollment cohort, Journal of the American College of Cardiology, 35, 96-105.

67. Fuchs, C. S., Stampfer, M. J., Colditz, G. A., Giovannucci, E. L., Manson, J. E., KaWACHI, I. et al. (1995) Alcohol consumption and mortality among women, The New England Journal of Medicine, 332, 1245-1250.

68. SHAPER, A. (1990) Alcohol and mortality: a review of prospective studies, British Journal of Addiction, 85, 837-847.

69. Laslett, A. M., Catalano, P., Chikritzhs, T., Dale, C., Doran, C., Ferris, J. et al. (2010) The range and magnitude of alcohol's harm to others (Fitzroy, Australia, Turning Point Alcohol \& Drug Centre).

70. Rothman, K. J., GreenLAND, S. \& LASH, T. L. (2008) Modern Epidemiology, 3rd ed (Philadelphia, USA, Lippincott Williams \& Wilkins).

This article is protected by copyright. All rights reserved. 
71. Holmes, J., Angus, C., BuykX, P., Ally, A., Stone, T., Meier, P. et al. (2016) Mortality and morbidity risks from alcohol consumption in the UK: Analyses using the Sheffield Alcohol Policy Model (v.2.7) to inform the UK Chief Medical Officers' review of the UK lower risk drinking guidelines, Sheffield, UK: Sheffield, U. o.

72. Rehm, J., Room, R., Monteiro, M., Gmel, G., Graham, K., ReHn, N. et al. (2004) Alcohol Use, in: Ezzati, M., Lopez, A. D., Rodgers, A. \& Murray, C. J. L. (Eds.) Comparative quantification of health risks: global and regional burden of disease attributable to selected major risk factors, pp. 959-1109 (Geneva, Switzerland, World Health Organization).

73. Lachenmeier, D. W. \& ReHM, J. (2015) Comparative risk assessment of alcohol, tobacco, cannabis and other illicit drugs using the margin of exposure approach, Scientific Reports, 5, 8126.

74. ANDERSON, P., CHISHOLM, D. \& FUHR, D. (2009) Effectiveness and cost-effectiveness of policies and programmes to reduce the harm caused by alcohol, Lancet, 373, 2234-2246.

This article is protected by copyright. All rights reserved. 
(A) Estonia

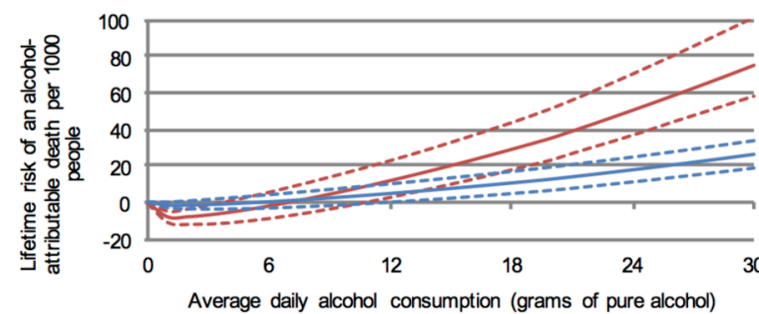

(B) Finland

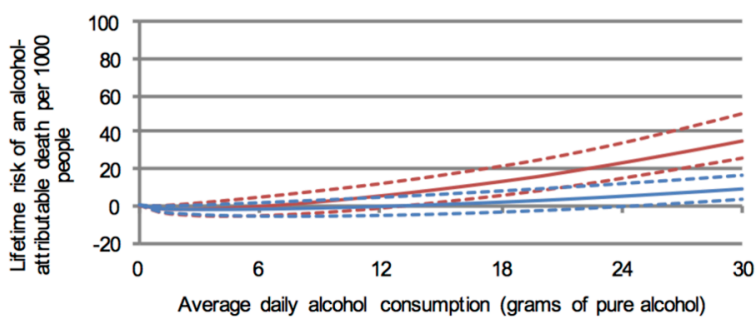

(C) Germany

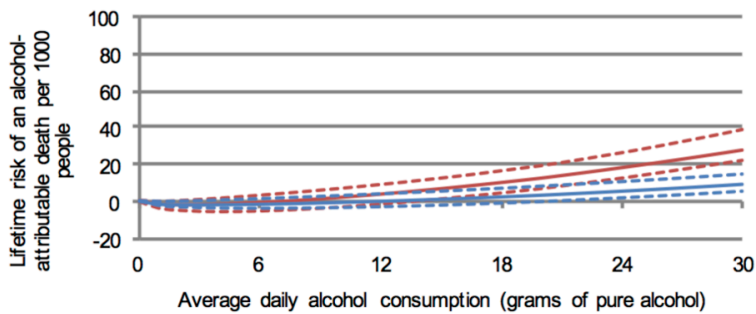

(D) Hungary

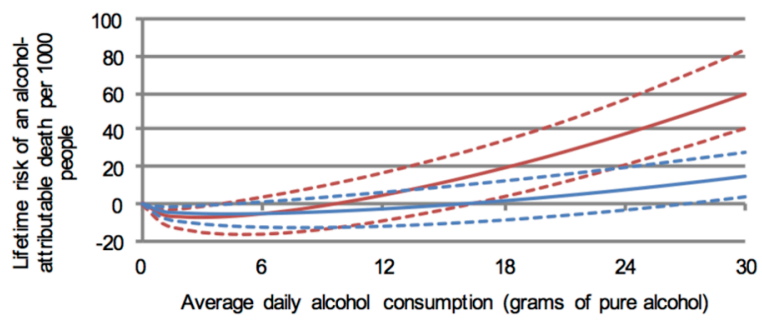

ADD_13827_f1.tiff
(E) Ireland

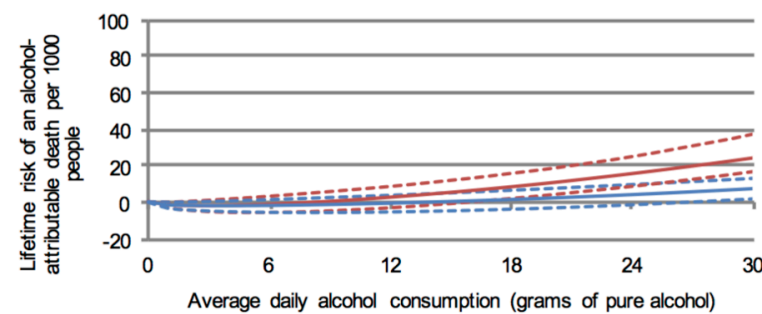

(F) Italy

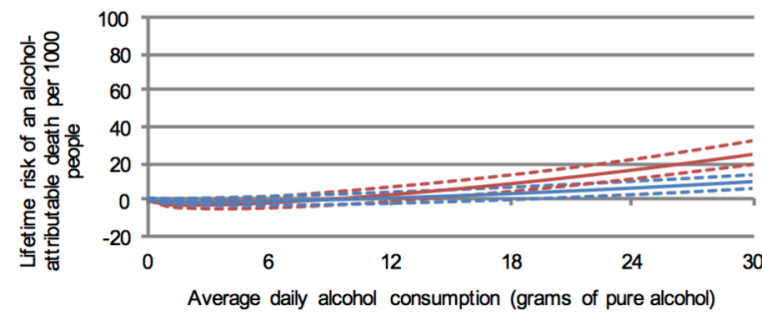

(G) Poland

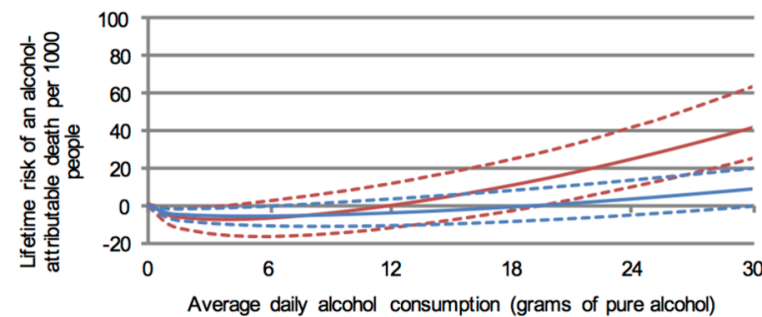




\section{University Library}

\section{- M I N E R VA}

\section{A gateway to Melbourne's research publications}

Minerva Access is the Institutional Repository of The University of Melbourne

Author/s:

Shield, KD;Gmel, G;Gmel, G;Makela, P;Probst, C;Room, R;Rehm, J

Title:

Life-time risk of mortality due to different levels of alcohol consumption in seven European countries: implications for low-risk drinking guidelines

\section{Date:}

2017-09-01

\section{Citation:}

Shield, K. D., Gmel, G., Gmel, G., Makela, P., Probst, C., Room, R. \& Rehm, J. (2017). Lifetime risk of mortality due to different levels of alcohol consumption in seven European countries: implications for low-risk drinking guidelines. ADDICTION, 112 (9), pp.1535-1544. https://doi.org/10.1111/add.13827.

Persistent Link:

http://hdl.handle.net/11343/292813 